BMJ Open Sport \& Exercise Medicine

\section{Impact of physical exercise intervention and PPAR $\gamma$ genetic polymorphisms on cardio-metabolic parameters among a Chinese youth population}

To cite: Su J, Wang H, Tian Y, et al. Impact of physical exercise intervention and PPAR $\gamma$ genetic polymorphisms on cardio-metabolic parameters among a Chinese youth population. BMJ Open Sport \& Exercise Medicine 2020;6:e000681. doi:10.1136/ bmjsem-2019-000681

- Additional material is published online only. To view please visit the journal online (http://dx.doi.org/10.1136/ bmjsem-2019-000681)

Accepted 8 March 2020

Check for updates

C) Author(s) (or their employer(s)) 2020. Re-use permitted under CC BY-NC. No commercial re-use. See rights and permissions. Published by BMJ.

${ }^{1}$ Department of Physical Education, Nanjing University of Aeronautics and Astronautics, Nanjing, China

${ }^{2}$ Department of Epidemiology, School of Public Health, Nanjing Medical University, Nanjing, China

${ }^{3}$ Department of Clinical Laboratory, Affiliated Hospital of Nanjing University of Chinese Medicine, Nanjing, China ${ }^{4}$ Center for Pathophysiology, School of Basic Medicine and Clinical Pharmacy, China Pharmaceutical University, Nanjing, China

Correspondence to Dr Chong Shen; sc100@126.com

Dr Harvest F Gu; feng.gu@cpu.edu.cn

\section{ABSTRACT}

Objective Physical inactivity inChinese youth students particularly in senior high schools, who participate inthe National Higher Education Entrance Examination (NCEE) is very common. Inorder to explore the beneficial effects from physical exercise and education afterNCEE, we performed a Physicalexercise Intervention Program in the Youth (PiPy) to evaluate the interaction with PPARy genetic variants on cardiovascular and metabolicparameters.

Methods A total of 772 freshmen (males 610/

females162) from high schools to university were recruited into the PiPy cohort, which was designedaccording to the National Student Health Standards in China. Anthropometric data were collected, whilephysical activities and body composition at the baseline of PiPy cohort weremeasured with SECAprotocols. Eighttagged single nucleotide polymorphisms (SNPs) in the PPARy gene were genotyped with TaqMan allelicdiscrimination.

Results After physical exercise intervention forthree months, in parallel with increased physical activities, BMI and skeletalmuscle content in all subjects was enhanced, while heart rate and bloodpressures were decreased. Furthermore, SNPs in 5'-UTR of the PPARy gene, including rs2920502,rs9817428 and rs2972164, were found to be associated with the changes of BMI.Body weight in the subjects with $\mathrm{BMI}<18.5$ and $18.5-23.9 \mathrm{~kg} / \mathrm{m}^{2}$ were increased, while the obese subjects $\left(\mathrm{BMI} \geq 24.0 \mathrm{~kg} / \mathrm{m}^{2}\right.$ ) decreased.

Conclusion The present study for the first timedemonstrated that the PiPy could improve cardiometabolic parameters such asheart rate, blood pressures and BMl for Chinese youth students after NCEE, inwhich the genetic interactive effects of PPAR $y$ should be included into obesityintervention.

\section{INTRODUCTION}

The youth is the future. Physical inactivity in the youth, however, has become a global public health problem. ${ }^{1-3}$ In the mainland of China, there are annually around 9 million of students from senior high schools, who participate in the National Higher Education Entrance Examination (NCEE). ${ }^{4}$ The competition of NCEE is extremely strong

\section{What are the new findings?}

- Physical inactivity in Chinese youth students particularly in senior high schools, who participate in the National Higher Education Entrance Examination (NCEE) is very common. To explore the beneficial effects from physical exercise and education after NCEE, we performed a Physical exercise Intervention Programme in the Youth (PiPy).

- The present study for the first time demonstrated that the PiPy could improve not only physical activities but also cardio-metabolic parameters such as heart rate, blood pressures and BMl for Chinese youth students after NCEE.

- PPARy genetic polymorphisms were interacted with the improved cardio-metabolic parameters in the PiPy, which suggests that it is necessary to combine with molecular genetic analysis for evaluation of benefit effects of a physical exercise and intervention programme.

because education has been highly valued as the major pathway to social success according to traditional Chinese culture for thousands of years. The students are trapped by heavy homework and exams and subsequently the inactivity of physical exercise among them is very common. ${ }^{56}$ It is worth reminding that this pattern of physical inactivity in China may have been taken for several years. Evidence has demonstrated that physical inactivity is a modifiable risk factor for lifestyle-related metabolic syndromes and chronic diseases, and may also track through their adulthood, midlife and old age. ${ }^{7-12}$ Physical exercise intervention is of importance in the improvement of muscular fitness, body composition, cardiovascular and metabolic health biomarkers in the youth, particularly in the freshmen who are from senior high school to university. ${ }^{13}$ Therefore, it is necessary to investigate the beneficial effects of physical exercise intervention programme in the improvement of body fitness, composition and cardio-metabolic 
parameters for the youth in Chinese populations particularly after NCEE.

Physical activity levels and exercise effects are influenced by biological factors and genetic variation. The estimated heritability of physical activity in adults ranges from approximately $20 \%$ to $90 \% .{ }^{14}$ Peroxisome proliferatoractivated receptor (PPAR $\gamma$ ) is preferentially expressed in adipose tissue, colon and macrophages and plays an important role in the regulation of fatty acid storage, glucose metabolism and cardiovascular activity. ${ }^{15} 16$ The PPARy gene is located in human chromosome 3p25.2. Two decades ago, a non-synonymous single nucleotide polymorphism (SNP) rs1801282 (C/G, Pro12Ala) was found to be associated with decreased receptor activity, lower body mass index (BMI) and improved insulin sensitivity in obesity and type 2 diabetes (T2D) among Caucasians populations. ${ }^{17} 18$ Later on, this SNP and its haplotype constructed with other SNPs are found to be associated with cancer and atherosclerosis. ${ }^{19-21}$ One decade ago, a hypertrophic effect of allele 12Ala of this polymorphism was detected in muscle fibres. ${ }^{22}$ Therefore, we have a hypothesis that PPARy genetic polymorphisms may play an interactive effect in the physical exercise intervention.

In the present study, we began with a Physical exercise Intervention Programme in the Youth (PiPy) for the freshmen who entered into the university after NECC. We then measured body compositions, cardiovascular and metabolic parameters from the baseline to PiPy. Finally, we analysed the interaction between the PiPy and PPARy genetic polymorphisms. The present study aimed to provide new information for better understanding the importance of physical exercise and PPARy genetic influence for intervention of physical inactivity in the youth, particularly, from the mainland of China.

\section{MATERIAL AND METHODS}

\section{Subjects}

A total of 772 freshmen (610 males and 162 females) from Nanjing University of Aeronautics and Astronautics, China were enrolled in the present study. Informed consent for the study was obtained from all participants. After then, they were interviewed with the predesigned electronic questionnaire regarding their demographic information, food habits and physical activity and also included in the physical examination for admission of the study. Physiological characteristics of all subjects are represented in table 1 .

\section{Physical exercise intervention program}

We designed the PiPy according to the national student health standards in China (http://www.csh.edu.cn/ wtzx/zl/index.html). The programme included physical exercises of run $50 \mathrm{~m}$ (for both males and females), run $1000 \mathrm{~m}$ (for males) and $800 \mathrm{~m}$ (for females), standing long jump, handgrip, sit and reach, pull-up (for males) and sit-up (for females). Each physical exercise took $2 \times 45$ min weekly. The $50 \mathrm{~m}, 800 \mathrm{~m} 1000 \mathrm{~m}$ runs and standing long jump were tested in the track and field, respectively, and the stopwatch and tape measurer are used for direct measurement. The female subjects, who were at similar stages of the menstrual cycle, sat or stood on the playground but did not take part in the physical activity.

\section{Anthropometric data collection}

Body weight and height were determined by the trained staff using a calibrated digital scale equipment (STF5000, Tongfang Health, China). BMI was calculated by dividing body weight $(\mathrm{kg})$ with the square of height $\left(\mathrm{m}^{2}\right)$. The definition of obesity in Asian populations, including Chinese, according to BMI value is different from the criteria for European Caucasian. Chinese people with BMI value equal to or more than $28 \mathrm{~kg} / \mathrm{m}^{2}$ was considered to be obese, while less than 24 to be lean. BMI between 24 and $28 \mathrm{~kg} / \mathrm{m}^{2}$ was over-weight. Systolic and diastolic blood pressures (SBP and DBP) as well as heart rate were measured after the thrice rests in a seated position with electronic sphygmomanometer (HEM-7207, Omron, Germany) and each rest was taken for $5 \mathrm{~min}$. The measurements of SBP, DBP and heart rate were averaged, respectively.

Table 1 Characteristics of the subjects

\begin{tabular}{|c|c|c|c|c|c|}
\hline & All subjects & Male & Female & $\mathrm{T} / \chi^{2}$ & $P$ value \\
\hline $\mathrm{N}$ & 772 & 610 & 162 & & \\
\hline Age (years) & $18.65 \pm 0.60$ & $18.66 \pm 0.60$ & $18.58 \pm 0.58$ & 1.556 & 0.120 \\
\hline High (cm) & $171.81 \pm 8.00$ & $174.20 \pm 6.79$ & $162.82 \pm 5.42$ & 22.437 & $<0.001$ \\
\hline Body weight (kg) & $64.64 \pm 12.91$ & $67.29 \pm 12.63$ & $54.68 \pm 8.25$ & 125.261 & $<0.001$ \\
\hline $\mathrm{BMI}\left(\mathrm{kg} / \mathrm{m}^{2}\right)$ & $21.83 \pm 3.54$ & $22.13 \pm 3.66$ & $20.61 \pm 2.74$ & 5.806 & $<0.001$ \\
\hline SBP (mm Hg) & $116.85 \pm 11.00$ & $118.86 \pm 10.65$ & $109.10 \pm 8.62$ & 11.049 & $<0.001$ \\
\hline DBP (mm Hg) & $68.02 \pm 7.05$ & $68.16 \pm 7.18$ & $67.49 \pm 6.53$ & 0.966 & 0.335 \\
\hline Heart rate (bmp) & $82.88 \pm 12.70$ & $81.38 \pm 12.19$ & $88.48 \pm 13.05$ & 5.567 & $<0.001$ \\
\hline Smoking & $10(1.30 \%)$ & $8(1.31 \%)$ & $2(1.23 \%)$ & 0.007 & 0.934 \\
\hline Alcohol drinking & $96(12.44 \%)$ & $90(14.75 \%)$ & $6(3.70 \%)$ & 14.486 & $<0.001$ \\
\hline
\end{tabular}

BMI, body mass index; DBP, diastolic blood pressure; SBP, systolic blood pressure. 


\section{Measurement of physical exercise and body composition}

In addition to height and weight, measurement of physical activities, including the tests for vital capacity index (ratio of vital capacity to body weight), sitting forward bend, maximum grip strength of one arm by using instruments for vital capacity, sitting body forward bending and grip strength (all from HengKangJiaYe, Shenzhen, China). The medical measuring systems and scales for body compositions such as fat mass, body water and muscle mass were applied with SECA mBCA 515 (SECA, Hamburg, Germany).

\section{Blood sampling and DNA extraction}

Peripheral blood samples were collected from each subject. Genomic DNA of blood samples was extracted using a DNeasy blood extraction protocol according to the manufacturer's instruction (Eaglink, Nanjing, China) and quantified with a NanoDrop 2000 spectrophotometer (Thermo Scientific, Massachusetts, USA).

\section{SNP selection and genotyping in the PPAR $\gamma$ gene}

We selected eight SNPs in the PPARy gene for the present study according to the following criteria: (1) the minor allele frequency (MAF) of SNP was more than 5\%; (2) the linkage disequilibrium for inferred Tagging SNP $\mathrm{r}^{2}>0.8$ was used; (3) all data were adopted from the record of Han Chinese in Beijing in dbSNP database (National Institute of Health, Bethesda, USA) (https:// www.ncbi.nlm.nih.gov/projects/SNP/). Consequently, eight tag SNPs, including one synonymous SNP that is, rs2920502, rs9817428, rs1263454, rs2972164, rs13433696 and rs1801282 (Ala12Pro), rs1175543 and rs3856806 in the PPARy gene were included in the genotyping experiments. The structure of the PPARy gene and positions of all studied SNPs from 5'-flanking to 3'-flanking sequences along the gene are represented in figure 1. PCR amplification and postreading three genotypes of the studied SNPs in the PPARy gene were performed using the allelic discrimination assays and the genotypes were read on the ABI 7900 system using the Sequence Detection System
V.2.1 software (Applied BioSystems, Foster City, California, USA). DNA template used in each sample was $10 \mathrm{ng}$ and the successful call rates of SNPs were approximately $99.4 \%$.

\section{Statistical analysis}

The student t-test was carried out to compare the differences between two groups. Fisher's exact test was used to test for the Hardy-Weinberg equilibrium. The genotype and allele frequencies between the groups were compared using $\chi^{2}$ tests. The comparison of BMI, heart rate and blood pressures among different genotypes was performed with ANOVA, and a general linear regression was used to adjust for covariates. Logistic regression model was fit to estimate the association of PPARy polymorphisms and the variation of elevated blood pressure status with the OR and 95\% CIs. Bonferroni correction was used for multiple comparisons. All of the statistical analyses were performed with SPSS V.15.0. Continuous variates were presented as means \pm SD. A two-tailed $\mathrm{p}<0.05$ was considered as statistically significant.

\section{Patient and public involvement}

Patients and/or the public were not involved in the design, or conduct, or reporting, or dissemination plans of this research.

\section{RESULTS \\ Improvement of physiological parameters and physical activities after PiPy}

After the PiPy programme, physiological parameters and physical activities in the subjects were improved in comparison with the records from the baseline. Analysis of physiological parameters and body compositions in males and females was performed respectively. The changes of physiological characteristic and physical activities of all subjects (males and females) from the base-line to PiPy are summarised in table 2. Physical exercises, including run $50 \mathrm{~m}$, run $800 \mathrm{~m}$ (females only), standing long jump, handgrip, sit and reach, pull-up and sit-up

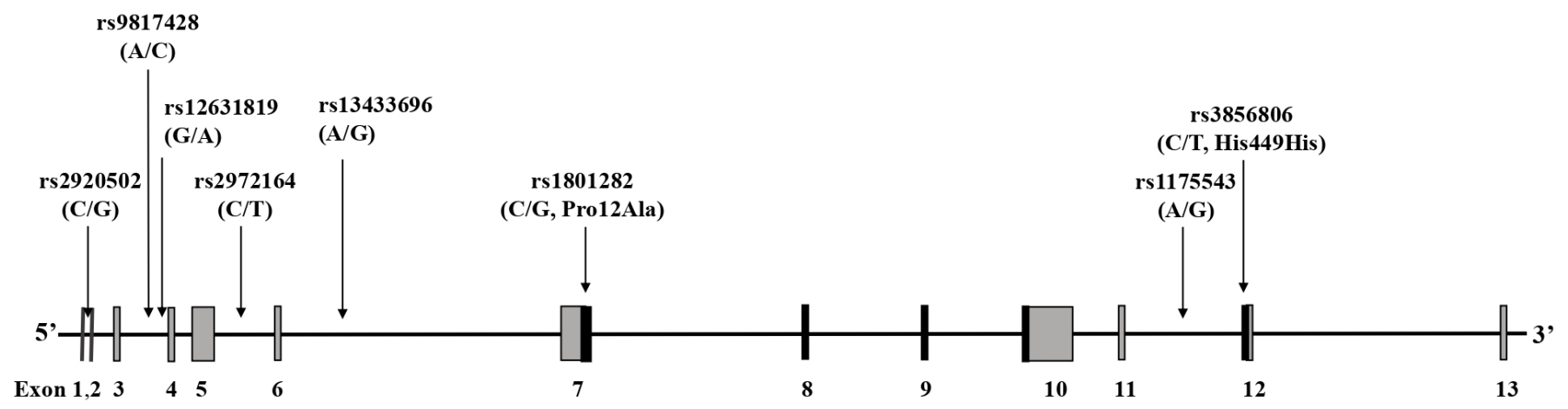

Figure 1 The PPARy gene structure and the positions of single nucleotide polymorphisms. The PPAR gene consists of 13 exons. In this gene, There are 5'-UTR in exons 1-7 and $3^{\prime}$-UTR in exons 10-13. There are two non-synonymous SNPs that is, rs1801282 (C/G, Pro12Ala) and rs3856806 (C/T, His449His). Five intronic SNPs, including rs2920502(C/G), rs9817428 (A/C), rs12631819 (G/A), rs2972164 (C/T) and rs13433696 (A/G) are located from exon 1 to exon 6, while one SNP rs1175543 (A/G) resides in intron 11. The coding exons are highlighted in dark and untranslated exons in grey. PPAR, peroxisome proliferatoractivated receptor; SNP, single nucleotide polymorphism; UTR, untranslated region. 
Table 2 Physical exercises, characteristic and body composition changes and of the subjects from the baseline to PiPy

\begin{tabular}{|c|c|c|c|c|}
\hline & Base-line & PiPy & $\begin{array}{l}\text { Changes for all subjects/ } \\
\text { males/females }\end{array}$ & P-values \\
\hline All (male/female) & $772(610 / 162)$ & $772(610 / 162)$ & & \\
\hline $\mathrm{BMI}\left(\mathrm{kg} / \mathrm{m}^{2}\right)$ & $\begin{array}{l}21.8 \pm 3.5 \\
(22.1 \pm 3.7 / 20.6 \pm 2.7)\end{array}$ & $\begin{array}{l}22.2 \pm 3.3 \\
(22.4 \pm 3.3 / 21.4 \pm 2.9)\end{array}$ & $\begin{array}{l}0.4 \pm 1.0 \\
(0.3 \pm 0.9 / 0.8 \pm 1.3)\end{array}$ & $\begin{array}{l}<0.001 \\
(<0.001 /<0.001)\end{array}$ \\
\hline $\mathrm{SBP}(\mathrm{mm} \mathrm{Hg})$ & $\begin{array}{l}116.8 \pm 11.0 \\
(118.9 \pm 10.6 / 108.9 \pm 8.6)\end{array}$ & $\begin{array}{l}114.6 \pm 11.5 \\
(115.9 \pm 11.2 / 107.0 \pm 9.6)\end{array}$ & $\begin{array}{l}-3.2 \pm 9.6 \\
(-3.4 \pm 9.8 /-2.3 \pm 8.5)\end{array}$ & $\begin{array}{l}<0.001 \\
(<0.001 / 0.002)\end{array}$ \\
\hline $\mathrm{DBP}(\mathrm{mm} \mathrm{Hg})$ & $\begin{array}{l}68.0 \pm 7.0 \\
(68.1 \pm 7.1 / 67.4 \pm 6.5)\end{array}$ & $\begin{array}{l}65.2 \pm 8.9 \\
(65.5 \pm 9.0 / 64.1 \pm 8.4)\end{array}$ & $\begin{array}{l}-2.9 \pm 8 \\
(-2.7 \pm 8 /-3.5 \pm 7.9)\end{array}$ & $\begin{array}{l}<0.001 \\
(<0.001 /<0.001)\end{array}$ \\
\hline Heart rate (bpm) & $\begin{array}{l}82.8 \pm 12.7 \\
(81.4 \pm 12.2 / 88.4 \pm 13.1)\end{array}$ & $\begin{array}{l}72.5 \pm 12.7 \\
(71.3 \pm 10.6 / 77.0 \pm 9.5)\end{array}$ & $\begin{array}{l}-10.4 \pm 11.2 \\
(-10.2 \pm 10.9 /-11 \pm 12.2)\end{array}$ & $\begin{array}{l}<0.001 \\
(<0.001 /<0.001)\end{array}$ \\
\hline Run 50 m (sec) & $\begin{array}{l}7.93 \pm 0.94 \\
(7.53 \pm 0.50 / 9.41 \pm 0.69)\end{array}$ & $\begin{array}{l}7.88 \pm 3.29 \\
(7.43 \pm 0.41 / 9.57 \pm 0.63)\end{array}$ & $\begin{array}{l}-0.15 \pm 0.41 \\
(-0.09 \pm 0.36 /-0.4 \pm 0.49)\end{array}$ & $\begin{array}{l}<0.001 \\
(<0.001 /<0.001)\end{array}$ \\
\hline $\begin{array}{l}\text { Run } 1000 \mathrm{~m} \text { for } \\
\text { males (min) }\end{array}$ & $4.08 \pm 0.51$ & $3.68 \pm 0.39$ & $-0.39 \pm 0.46$ & $<0.001$ \\
\hline $\begin{array}{l}\text { Run } 800 \mathrm{~m} \text { for } \\
\text { females (min) }\end{array}$ & $3.99 \pm 0.43$ & $3.47 \pm 0.71$ & $-0.52 \pm 0.69$ & $<0.001$ \\
\hline $\begin{array}{l}\text { Standing long } \\
\text { jump }(\mathrm{cm})\end{array}$ & $\begin{array}{l}206.04 \pm 29.99 \\
(217.76 \pm 20.37 / 161.49 \pm 15.72)\end{array}$ & $\begin{array}{l}218.12 \pm 30.14 \\
(230.54 \pm 18.73 / 170.95 \pm 15.23)\end{array}$ & $\begin{array}{l}12.08 \pm 12.77 \\
(12.78 \pm 13.06 / 9.47 \pm 10.78)\end{array}$ & $\begin{array}{l}<0.001 \\
(<0.001 /<0.001)\end{array}$ \\
\hline Handgrip (n) & $\begin{array}{l}34.26 \pm 9.15 \\
(37.30 \pm 7.46 / 23.38 \pm 5.45)\end{array}$ & $\begin{array}{l}39.52 \pm 11.32 \\
(43.01 \pm 9.67 / 27.06 \pm 6.70)\end{array}$ & $\begin{array}{l}5.26 \pm 8.91 \\
(5.70 \pm 9.04 / 3.68 \pm 7.81)\end{array}$ & $\begin{array}{l}<0.001 \\
(<0.001 /<0.001)\end{array}$ \\
\hline $\begin{array}{l}\text { Sit and reach } \\
\text { (cm) }\end{array}$ & $\begin{array}{l}8.04 \pm 7.94 \\
(7.35 \pm 7.90 / 10.95 \pm 7.31)\end{array}$ & $\begin{array}{l}15.37 \pm 7.70 \\
(14.71 \pm 7.82 / 18.01 \pm 6.63)\end{array}$ & $\begin{array}{l}7.33 \pm 6.83 \\
(7.37 \pm 6.81 / 7.06 \pm 6.89)\end{array}$ & $\begin{array}{l}<0.001 \\
(<0.001 /<0.001)\end{array}$ \\
\hline $\begin{array}{l}\text { Pull-up for } \\
\text { males }(n)\end{array}$ & $3.53 \pm 3.75$ & $5.45 \pm 4.21$ & $1.92 \pm 3.08$ & $<0.001$ \\
\hline $\begin{array}{l}\text { Sit-up for } \\
\text { females (n) }\end{array}$ & $32.33 \pm 10.38$ & $35.70 \pm 8.54$ & $3.37 \pm 7.73$ & $<0.001$ \\
\hline $\begin{array}{l}\text { Relative fat } \\
\text { value (\%) }\end{array}$ & $\begin{array}{l}18.10 \pm 9.15 \\
(15.36 \pm 7.99 / 28.42 \pm 4.84)\end{array}$ & $\begin{array}{l}19.4 \pm 8.23 \\
(16.89 \pm 7.06 / 28.94 \pm 4.62)\end{array}$ & $\begin{array}{l}1.289 \pm 3.023 \\
(1.5 \pm 3.208 / 0.488 \pm 1.997)\end{array}$ & $\begin{array}{l}<0.001 \\
(<0.001 / 0.002)\end{array}$ \\
\hline $\begin{array}{l}\text { Absolute fat } \\
\text { value (\%) }\end{array}$ & $\begin{array}{l}12.119 \pm 7.381 \\
(11.133 \pm 7.626 / 15.833 \pm 4.834)\end{array}$ & $\begin{array}{l}13.078 \pm 6.893 \\
(12.12 \pm 7.00 / 16.71 \pm 5.02)\end{array}$ & $\begin{array}{l}0.957 \pm 2.400 \\
(0.987 \pm 2.583 / 0.843 \pm 1.513)\end{array}$ & $\begin{array}{l}<0.001 \\
(<0.001 /<0.001)\end{array}$ \\
\hline Visceral fat (\%) & $\begin{array}{l}1.31 \pm 0.76 \\
(1.39 \pm 0.83 / 1.02 \pm 0.22)\end{array}$ & $\begin{array}{l}1.28 \pm 0.66 \\
(1.35 \pm 0.72 / 1.03 \pm 0.20)\end{array}$ & $\begin{array}{l}-0.02 \pm 0.46 \\
(-0.03 \pm 0.51 / 0.01 \pm 0.13)\end{array}$ & $\begin{array}{l}0.150 \\
(0.132 / 0.745)\end{array}$ \\
\hline $\begin{array}{l}\text { Skeletal muscle } \\
\text { content (\%) }\end{array}$ & $\begin{array}{l}10.399 \pm 2.686 \\
(11.501 \pm 1.728 / 6.254 \pm 1.172)\end{array}$ & $\begin{array}{l}10.673 \pm 2.497 \\
(11.7 \pm 1.561 / 6.766 \pm 1.177)\end{array}$ & $\begin{array}{l}0.248 \pm 0.643 \\
(0.179 \pm 0.64 / 0.513 \pm 0.586)\end{array}$ & $\begin{array}{l}<0.001 \\
(<0.001 /<0.001)\end{array}$ \\
\hline
\end{tabular}

BMI, body mass index; DBP, diastolic blood pressure; PiPy, Physical exercise Intervention Program in the Youth; SBP, systolic blood pressure.

from the base-line to PiPy were significantly improved $(\mathrm{p}<0.001$, all $)$. Run $1000 \mathrm{~m}$ in male subjects was recorded as $4.08 \pm 0.51 \mathrm{~min}$ in the baseline and $3.68 \pm 0.39 \mathrm{~min}$ after PiPy and the change was statistically significant $(\mathrm{p}<0.001)$.

Data of physiological parameters and body composition demonstrated that BMI in all subjects from the baseline to PiPy was enhanced from $21.8 \pm 3.5(22.1 \pm 3.7 / 20.6 \pm 2.7)$ to $22.2 \pm 3.3(22.4 \pm 3.3 / 21.4 \pm 2.9) \mathrm{kg} / \mathrm{m}^{2}(\mathrm{p}<0.001)$, while SBP and DBP were significantly decreased respectively from $117 \pm 11$ and $68 \pm 7$ to $115 \pm 12$ and $65 \pm 9 \mathrm{~mm} \mathrm{Hg}$ $(\mathrm{p}<0.001$ both). Heart rate was also found to decreased in the subjects after PiPy $(83 \pm 13$ vs $73 \pm 11 \mathrm{bpm}, \mathrm{p}<0.001)$. Furthermore, we found that skeletal muscle content in all subjects from the baseline to PiPy was increased $(10.399 \pm 2.686$ vs $10.673 \% \pm 2.497 \%, \mathrm{p}<0.001)$. Both relative and absolute fat values in all subjects were increased
( $18.10 \pm 9.15$ vs $19.4 \pm 8.23 ; 12.12 \pm 7.38$ vs $13.08 \% \pm 6.89 \%$, $\mathrm{p}<0.001$ both $)$ but not visceral fat value $(1.31 \pm 0.76$ vs $1.28 \% \pm 0.66 \%, \mathrm{p}=0.150)$ and non-fat content $(52.11 \pm 9.99$ vs $52.46 \% \pm 8.51 \%, \mathrm{p}=0.110$ ). Comparison analyses for changes of other characteristics for all subjects in term of improvement of physical activities, physiological parameters and body compositions were done and the data were summarised in online supplementary table 1. Furthermore, the data from correlation analysis of body weight, BMI, SBP, DBP and heart rate at baseline and PiPy were summarised in online Supplementary Table S2A and B.

\section{Impact of metabolic parameters after PiPy and interacted with PPAR $\gamma$ genetic effects}

We genotyped eight PPARy gene polymorphisms in the PiPy cohort. The allele frequencies of all studied SNPs 


\begin{tabular}{|c|c|c|c|c|c|}
\hline SNP id & SNP type & Chr position & Molecule type & Function & MAF \\
\hline rs2920502 & $S=C / G$ & 3:12 287696 & Genomic & Intronic and in 5'-UTR & 0.332 \\
\hline rs2972164 & $\mathrm{Y}=\mathrm{C} / \mathrm{T}$ & 3:12 292917 & Genomic & Intronic and in 5'-UTR & 0.418 \\
\hline rs9817428 & $M=A / C$ & 3:12 298768 & Genomic & Intronic and in 5'-UTR & 0.479 \\
\hline rs12631819 & $\mathrm{D}=\mathrm{G} / \mathrm{A}$ & 3:12 301362 & Genomic & Intronic and in 5'-UTR & 0.406 \\
\hline rs13433696 & $R=A / G$ & 3:12 316993 & Genomic & Intronic and in $5^{\prime}$-UTR & 0.335 \\
\hline rs1801282 & $\mathrm{S}=\mathrm{C} / \mathrm{G}$ & 3:12 351626 & cDNA & Missense Pro12Ala & 0.065 \\
\hline rs1175543 & $R=A / G$ & 3:12 424934 & Genomic & Intronic & 0.439 \\
\hline rs3856806 & $Y=C / T$ & 3:12 434058 & cDNA & Cds-synon His449His & 0.218 \\
\hline
\end{tabular}

Nucleotide and amino acid codes are provided by International Union of Pure and Applied Chemistry. Contig accession number for chromosomal position is NT_022517.19 in GRCh38.p7.

MAF, minor allele frequency; PiPy, physical exercise Intervention Program in the Youth; PPAR $\gamma$, peroxisome proliferator-activated receptor gamma; SNP, single nucleotide polymorphism; UTR, untranslated region.

were listed in table 3. In this cohort, the MAFs of most of the studied SNPs were relatively high $(21.8 \%-47.9 \%)$ but SNP rs1801282 Pro12Ala had low MAF (6.5\%).

To explore the interaction between the PiPy and PPARy genetic polymorphisms, we first analysed the altered metabolic parameters according to the values of BMI that is, BMI $<18.5,18.5-23.9$ and $\geq 24.0 \mathrm{~kg} / \mathrm{m}^{2}$. Data demonstrated that heart rate, systolic and diastolic blood pressures in all subgroups of subjects according to BMI values from the baseline to PiPy were decreased (table 4). Interestingly, body weight in the subjects with $\mathrm{BMI}<18.5$ and $18.5-23.9 \mathrm{~kg} / \mathrm{m}^{2}$ were found to be significantly increased, but the subjects with BMI value $\geq 24.0 \mathrm{~kg} / \mathrm{m}^{2}$ had body weight decreased $(26.98 \pm 2.58$ vs . $26.75 \pm 2.48$ $\mathrm{kg} / \mathrm{m}^{2}, \quad \mathrm{p}=0.006$ and $<0.001$ in males and females, respectively). Changes of physical strength and body components in the subjects from the baseline to PiPy according to BMI values were attached in online supplementary table 3 . Furthermore, we analysed the changes of BMI in each subgroup of subjects according to the genotypes of PPAR $\gamma$ polymorphisms. Figure 2 showed that SNP rs2972164 $\mathrm{T}$ allele increased the reduction of BMI in the range of $\mathrm{BMI} \geq 28 \mathrm{~kg} / \mathrm{m}^{2}(\mathrm{p}=0.005)$, while each additional copy of minor allele $\mathrm{C}$ of rs 9817428 decreased the reduction of BMI in the range of BMI $\geq 28 \mathrm{~kg} / \mathrm{m}^{2}$. Additionally, SNP rs2920502 significantly impacted in BMI $(\mathrm{p}<0.05)$. Each additional copy of the minor allele G of rs2920502 increased the reduction of $\mathrm{BMI}$ in the range of $\mathrm{BMI} \geq 28$ $\mathrm{kg} / \mathrm{m}^{2}(\mathrm{p}<0.05)$.

\begin{tabular}{|c|c|c|c|c|c|}
\hline Variable & BMI groups & Baseline & PiPy & Changes & $P$-value ${ }^{a / b}$ \\
\hline \multirow[t]{3}{*}{ Body weight (kg) } & $<18.5$ & $51.24 \pm 5.55$ & $53.38 \pm 5.74$ & $2.14 \pm 1.57$ & $<0.001$ \\
\hline & $18.5-23.9$ & $61.42 \pm 7.21$ & $62.70 \pm 7.07$ & $1.28 \pm 2.16$ & $<0.001$ \\
\hline & $\geq 24.0$ & $82.14 \pm 10.79$ & $81.07 \pm 10.27$ & $-1.07 \pm 2.94$ & $<0.001 /<0.001$ \\
\hline \multirow[t]{3}{*}{$\mathrm{BMI}\left(\mathrm{kg} / \mathrm{m}^{2}\right)$} & $<18.5$ & $17.42 \pm 0.89$ & $18.25 \pm 1.02$ & $0.83 \pm 0.60$ & $<0.001$ \\
\hline & $18.5-23.9$ & $20.97 \pm 1.48$ & $21.43 \pm 1.52$ & $0.46 \pm 0.79$ & $<0.001$ \\
\hline & $\geq 24.0$ & $26.98 \pm 2.58$ & $26.75 \pm 2.48$ & $-0.23 \pm 1.10$ & $0.006 /<0.001$ \\
\hline \multirow[t]{3}{*}{$\mathrm{SBP}(\mathrm{mm} \mathrm{Hg})$} & $<18.5$ & $111.16 \pm 10.71$ & $109.35 \pm 9.99$ & $-1.80 \pm 8.19$ & 0.036 \\
\hline & $18.5-23.9$ & $115.60 \pm 10.18$ & $112.42 \pm 11.07$ & $-3.18 \pm 9.70$ & $<0.001$ \\
\hline & $\geq 24.0$ & $123.42 \pm 10.16$ & $119.53 \pm 11.00$ & $-3.89 \pm 9.92$ & $<0.001 / 0.249$ \\
\hline \multirow[t]{3}{*}{ DBP (mm Hg) } & $<18.5$ & $67.32 \pm 7.65$ & $65.81 \pm 8.22$ & $-1.51 \pm 8.01$ & 0.073 \\
\hline & $18.5-23.9$ & $67.51 \pm 6.66$ & $64.70 \pm 9.28$ & $-2.81 \pm 8.28$ & $<0.001$ \\
\hline & $\geq 24.0$ & $69.74 \pm 7.40$ & $65.70 \pm 8.10$ & $-4.04 \pm 7.24$ & $<0.001 / 0.050$ \\
\hline \multirow[t]{3}{*}{ Heart rate (bmp) } & $<18.5$ & $85.59 \pm 13.73$ & $73.45 \pm 11.22$ & $-12.14 \pm 11.41$ & $<0.001$ \\
\hline & $18.5-23.9$ & $83.18 \pm 12.71$ & $72.75 \pm 10.69$ & $-10.43 \pm 11.51$ & $<0.001$ \\
\hline & $\geq 24.0$ & $80.38 \pm 11.64$ & $71.14 \pm 10.17$ & $-9.24 \pm 10.02$ & $<0.001 / 0.142$ \\
\hline
\end{tabular}

Groups are determined based on the BMI values at baseline; a comparison between the levels at baseline and after PiPy; b Comparison between males and females.

BMI, body mass index; DBP, diastolicblood pressure; PiPy, Physical exercise Intervention Program in the Youth; SBP, systolic blood pressure. 

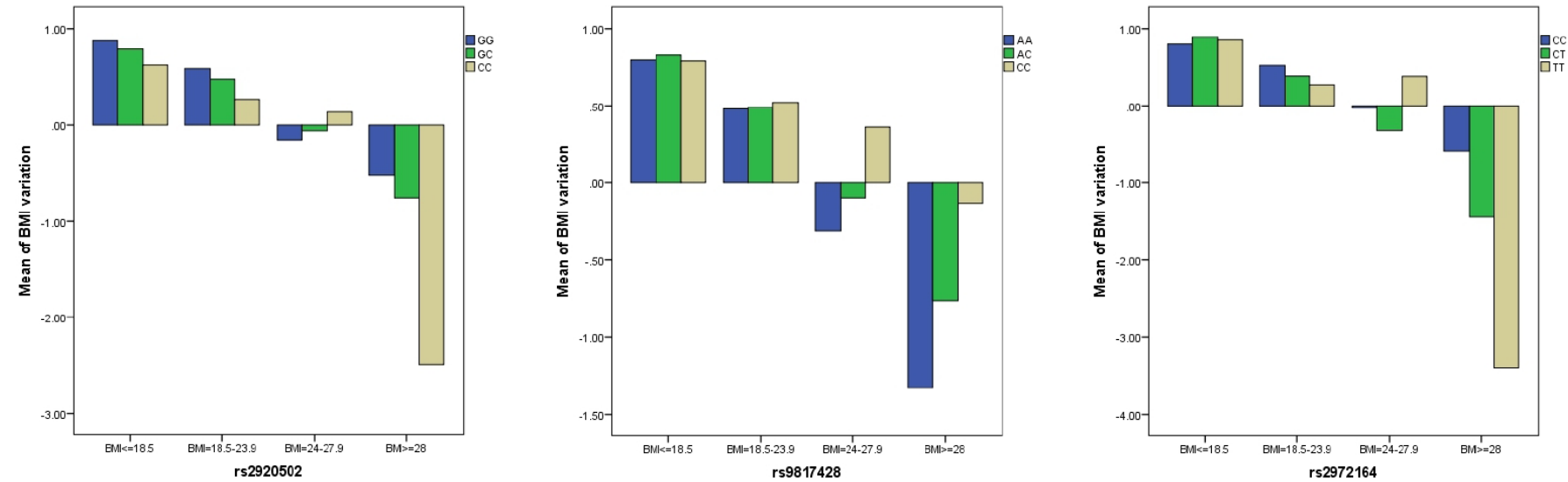

Figure 2 Changed BMI values according to the genotypes of PPARy genetic polymorphisms. Three SNPs that is, rs2920502, rs9817428 and rs2972164 were found to be interacted with changed metabolic parameter of BMI from the baseline to PiPy. In the subjects with BMI values $<18.5$ and $18.5-23.9 \mathrm{~kg} / \mathrm{m}^{2}$, these three SNPs were associated with increased BMI. The association pattern among the subjects with BMI value $24.0-27.9 \mathrm{~kg} / \mathrm{m}^{2}$ was found to be partially reversed. Furthermore, SNP rs2920502 had impact in BMI $(p<0.05)$. Each additional copy of the minor allele of this polymorphism increased the reduction of $\mathrm{BMI}$ in the range of $\mathrm{BMI} \geq 28 \mathrm{~kg} / \mathrm{m}^{2}(\mathrm{p}<0.05)$. SNP rs2972164 increased the reduction of $\mathrm{BMI}$ in the range of $\mathrm{BMl} \geq 28 \mathrm{~kg} / \mathrm{m}^{2}$ $(p=0.005)$, while each additional copy of minor allele of $r s 9817428$ decreased the reduction of $\mathrm{BMl}$ in the range of $\mathrm{BMl} \geq 28 \mathrm{~kg} /$ $\mathrm{m}^{2}$. BMI, body mass index; PiPy, Physical exercise Intervention Program in the Youth; SNP, single nucleotide polymorphism.

\section{DISCUSSION}

The future belongs to the youth. To improve the physical activities and physiological characteristics in Chinese youth who are freshmen from NCEE into university, in the present study, we have conducted the PiPy, a physical exercise intervention programme, together with a genetic study of PPAR $y$ and the effect of physical exercise. Results from our study indicated that this programme had the beneficial effects in body fitness, compositions and cardio-metabolic parameters among the youth subjects, while $P P A R$ y genetic effects were involved in the interaction.

Evidence has demonstrated that exercise intervention can reduce sympathetic excitability and increase arterial lumen diameter to reduce peripheral vascular resistance, lower blood pressures and exercise-induced changes in oxidative stress, endothelial function and inflammatory status can also affect blood pressures. ${ }^{23} 24$ A review of 13 136 subjects enrolled in 13 prospective cohorts revealed a dose-response relationship between amateur physical activity and the incidence of hypertension. ${ }^{25}$ Furthermore, Diaz et al showed that exercise-related physical activity from moderate to high intensity can effectively reduce the risk of hypertension. ${ }^{26}$ In the present study, we used physical exercise only as an indicator of physical activity and found that blood pressures of the subjects from the baseline to PiPy was significantly decreased, which was consistent with the previous reports. ${ }^{23} 24$ Resting heart rate was one of the indicators of cardiac autonomic function. Increased resting heart rate might lead to increased sympathetic excitability, activation of inflammatory pathways and endothelial dysfunction, and mediate adverse cardiovascular events through elevated blood pressure. ${ }^{27} 28$ Vazir et al reported that the risk of cardiovascular disease and cancer death increased by $9 \%-13 \%$, when heart rate was increased for five more. If heart rate was decreased, however, heart function could be improved. ${ }^{29}$ As similar with these studies, the present study demonstrated that the resting heart rate after the PiPy was significantly reduced, and remained within the normal range. In contrast to the male subjects with overweight (BMI >24), however, the females with overweight $(\mathrm{BMI}>24)$ had no statistically significant changes in heart rate and blood pressures probably due to their inadequate physical exercise and/or small sample size $(n=15)$.

Unlike most previous intervention programs of sport and diet, the present study was mainly based on physical education as an intervention but not mandate the subject's athletic content. In addition, the studied subjects were not limited to obese, which was conducive to the promotion of research results in the general youth population. This provided us the opportunity to evaluate the genetic effects of $P P A R y$ in the subgroups of subjects with different BMI values. We have genotyped all eight tagged SNPs in the PPARy gene. SNP 1801282 (C/G, Pro12Ala) is a non-synonymous polymorphism. Previous studies in Caucasian populations demonstrated that increased physical activity were associated with higher insulin sensitivity index in the carriers with allele 12Ala but not the subjects carrying with Pro12 homozygote genotype, ${ }^{15} 16$ while the regular exercise could improve glucose homeostasis and BMI in the subjects with T2D and obesity according to the derived phenotypes of PPAR polymorphisms. ${ }^{17} 18$ In the present study, we found that MAF of SNP $1801282(\mathrm{C} / \mathrm{G}$, Pro12Ala) in the PiPy cohort was low and no significant association of this polymorphism with blood pressures, heart rate and BMI was found. A meta-analysis indicated that the scenario of SNP 1801282 (C/G, Pro12Ala) was dominated in Caucasian but not Asian populations. Based on the information from previous and present studies, we suggested that SNP 1801282 (C/G, Pro12Ala) in the PPARy gene might be population specific. 
From the baseline to PiPy, the average body weight in whole study population were found to be increased. Data from further analysis of PPARy genetic polymorphisms, however, implicated that several SNPs, including rs2920502, rs9817428 and rs2972164 were that rs2972164, rs9817428 significantly associated with alternation of BMI in the subgroup of subjects with BMI ranged $\geq 28$ $\mathrm{kg} / \mathrm{m}^{2}$. Previously, Matsuo $\mathrm{T}$ conducted an association study of PPARy gene polymorphisms with weight reduction and changes in coronary heart disease risk factors in response to a 14-week calorie restriction and the data suggested that SNP rs1175544 of in this gene accounted for a significant portion of the total body weight reduction variance in response to a short-term intervention consisting of calorie restriction. ${ }^{30}$ Qian X et al performed a genetic study of PPARy gene in a Chinese population and reported that SNP rs2920502 was a protective factor of hypertension and metabolic syndrome, while SNPs rs9817428 and rs2972164 were associated with reduced risk of hypertension. ${ }^{31}$ These SNPs were located along exon 1 to 6 in $5^{\prime}$-UTR of the PPARy gene and their polymorphic alleles might influence binding factors or enhancers and subsequently altered the gene activity. However, we did not have opportunity to collect the muscle biopsy from volunteers for study of PPARy gene expression and related regulation.

There are several limitations in the present study. First, the sample size of females is small particularly for analysis in BMI subgroups. When some of female subjects were at the stages of menstrual cycle, they were arranged to view but not to participate in the physical activities of their classmates. Second, the students originally come from different provinces around China. The baselined dietary patterns among these students may be different. Although the accommodation and dining of all students who have participated in the PiPy were managed within the same campus, the rich and colourful menu of the university canteen included flavours from all over the country. Students were free to choose the dishes and no calorie limit for daily diet was included in the PiPy. Third, there was lack of plasma insulin levels in the studied subjects.

In conclusion, the present study for the first time demonstrated that the PiPy could improve not only physical activities but also cardio-metabolic parameters among Chinese youth students, in which PPARy genetic polymorphisms were interacted, particularly in the obese subjects. Based on the findings from the present study, we could have a perspective on PiPy. First, this programme is important for health improvement of the youth particularly in the mainland of China after NCEE, while the physical inactivity among the youth is common. Second, it is necessary to combine with molecular genetic analysis for evaluation of the benefit of the effects of a physical exercise and intervention programme such as PiPy because genetic variation in the population may influence the phenotypic parameters. Further investigation concerning the follow-up and epigenetic studies in this cohort has been taken into our consideration.

Acknowledgements The authors wish to thank Ms. Chunlan Liu and Yao Fan for excellent research assistance.

Contributors HFG proposed, and CS, JS and HFG designed the study. JS, HH and WG collected anthropometric data. HW and YT performed genotyping experiments. HFG, CS, HW, JS and HH interpreted data. HFG, SC and HW prepared the manuscript. All authors take responsibility for the integrity of data and accuracy of data analysis and have approved the final version of manuscript

Funding This study was supported by the research grant from Nanjing University of Aeronautics and Astronautics (NUAA-160830), Jiangsu Provincial Fourth "333 Project", the Priority Academic Programme for the Development of Jiangsu Higher Education Institutions (Public Health and Preventive Medicine) and the start grant of China Pharmaceutical University (CPU-180517).

Competing interests None declared.

Patient consent for publication Not required.

Ethics approval The ethics approval of the present study was obtained from Research Ethics Committee in Nanjing Medical University, China (No. 2016-290).

Provenance and peer review Not commissioned; externally peer reviewed.

Data availability statement Data are available upon reasonable request. All data relevant to the study are included in the article or uploaded as supplementary information. Data available as stated above.

Open access This is an open access article distributed in accordance with the Creative Commons Attribution Non Commercial (CC BY-NC 4.0) license, which permits others to distribute, remix, adapt, build upon this work non-commercially, and license their derivative works on different terms, provided the original work is properly cited, appropriate credit is given, any changes made indicated, and the use is non-commercial. See: http://creativecommons.org/licenses/by-nc/4.0/.

\section{ORCID iD}

Harvest F Gu http://orcid.org/0000-0003-4578-5449

\section{REFERENCES}

1 Guthold R, Ono T, Strong KL, et al. Worldwide variability in physical inactivity a 51-country survey. Am J Prev Med 2008;34:486-94.

2 Sallis JF, Cerin E, Conway TL, et al. Physical activity in relation to urban environments in 14 cities worldwide: a cross-sectional study. Lancet 2016;387:2207-17.

3 Darfour-Oduro SA, Buchner DM, Andrade JE, et al. A comparative study of fruit and vegetable consumption and physical activity among adolescents in 49 Low-and-Middle-Income countries. Sci Rep 2018;8:1623.

4 statistics E. Ministry of Education of the People's Republic of China Web site. Available: http://www.moe.gov.cn/publicfiles

5 Shi Z, Lien N, Kumar BN, et al. Physical activity and associated socio-demographic factors among school adolescents in Jiangsu Province, China. Prev Med 2006;43:218-21.

6 Chen Y, Zheng Z, Yi J, et al. Associations between physical inactivity and sedentary behaviors among adolescents in 10 cities in China. BMC Public Health 2014; 14:744.

7 Dyson PA, Anthony D, Fenton B, et al. Community interventions for health collaboration. high rates of child hypertension associated with obesity: a community survey in China, India and Mexico. Paediatr Int Child Health 2014;34:43-9.

8 Fogelholm M. Physical activity, fitness and fatness: relations to mortality, morbidity and disease risk factors. A systematic review. Obes Rev 2010;11:202-21.

9 Knight JA. Physical inactivity: associated diseases and disorders. Ann Clin Lab Sci 2012;42:320-37.

10 Nunan D, Mahtani KR, Roberts N, et al. Physical activity for the prevention and treatment of major chronic disease: an overview of systematic reviews. Syst Rev 2013;2:56.

11 Kruk J. Health and economic costs of physical inactivity. Asian Pac J Cancer Prev 2014;15:7499-503.

12 Yang YC, Boen C, Gerken K, et al. Social relationships and physiological determinants of longevity across the human life span. Proc Natl Acad Sci U S A 2016;113:578-83.

13 Evenson KR, Mota J. Progress and future directions on physical activity research among youth. J Phys Act Health 2011;8:149-51. 
14 Lefterova MI, Haakonsson AK, Lazar MA, et al. PPAR $\gamma$ and the global map of adipogenesis and beyond. Trends Endocrinol Metab 2014;25:293-302.

15 Santos GM, Neves FdeAR, Amato AA. Thermogenesis in white adipose tissue: an unfinished story about PPAR $\gamma$. Biochim Biophys Acta 2015;1850:691-5.

16 Deeb SS, Fajas L, Nemoto M, et al. A Pro12Ala substitution in PPAR $\gamma 2$ associated with decreased receptor activity, lower body mass index and improved insulin sensitivity. Nat Genet 1998;20:284-7.

17 Altshuler D, Hirschhorn JN, Klannemark M, et al. The common PPARgamma Pro12Ala polymorphism is associated with decreased risk of type 2 diabetes. Nat Genet 2000;26:76-80.

18 Smith WM, Zhou XP, Kurose K, et al. Opposite association of two PPARG variants with cancer: overrepresentation of $\mathrm{H} 449 \mathrm{H}$ in endometrial carcinoma cases and underrepresentation of P12A in renal cell carcinoma cases. Hum Genet 2001;109:146-51.

19 Landi S, Moreno V, Gioia-Patricola L, et al. Association of common polymorphisms in inflammatory genes interleukin (IL)6, IL8, tumor necrosis factor alpha, NFKB1, and peroxisome proliferatoractivated receptor gamma with colorectal cancer. Cancer Res 2003;63:3560-6.

20 Al-Shali KZ, House AA, Hanley AJG, et al. Genetic variation in PPARG encoding peroxisome proliferator-activated receptor gamma associated with carotid atherosclerosis. Stroke 2004;35:2036-40.

21 Ahmetov II, Mozhayskaya IA, Lyubaeva EV, et al. Pparg gene polymorphism and locomotor activity in humans. Bull Exp Biol Med 2008;146:630-2.

22 Sarzynski MA, Loos RJF, Lucia A, et al. Advances in exercise, fitness, and performance genomics in 2015. Med Sci Sports Exerc 2016;48:1906-16.
23 Hegde SM, Solomon SD. Influence of physical activity on hypertension and cardiac structure and function. Curr Hypertens Rep 2015;17:77.

24 Korsager Larsen M, Matchkov VV. Hypertension and physical exercise: the role of oxidative stress. Medicina 2016;52:19-27.

25 Huai $\mathrm{P}$, Xun $\mathrm{H}$, Reilly $\mathrm{KH}$, et al. Physical activity and risk of hypertension: a meta-analysis of prospective cohort studies. Hypertension 2013;62:1021-6.

26 Diaz KM. Booth JN 3rd, seals SR, Abdalla M, Dubbert PM, Sims M, Ladapo JA, Redmond N, Muntner P, Shimbo D. physical activity and incident hypertension in African Americans: the Jackson heart study. Hypertension 2017;69:421-7.

27 Liu L, Mizushima S, Ikeda K, et al. Cardiovascular disease and alimentary comparison study Group. resting heart rate in relation to blood pressure: results from the world health OrganizationCardiovascular disease and alimentary comparison study. Int J Cardiol 2010;145:73-4.

28 Aladin Al, Al Rifai M, Rasool SH, et al. The association of resting heart rate and incident hypertension: the Henry Ford Hospital exercise testing (fit) project. Am J Hypertens 2016;29:251-7.

29 Vazir A, Claggett B, Cheng S, et al. Association of resting heart rate and temporal changes in heart rate with outcomes in participants of the Atherosclerosis risk in Communities study. JAMA Cardiol 2018;3:200-6.

30 Matsuo T, Nakata Y, Katayama Y, et al. Pparg genotype accounts for part of individual variation in body weight reduction in response to calorie restriction. Obesity 2009;17:1924-31.

31 Qian X, Guo D, Zhou H, et al. Interactions between PPARG and AGTR1 gene polymorphisms on the risk of hypertension in Chinese Han population. Genet Test Mol Biomarkers 2018;22:90-7. 